\title{
Rebound Tonometry
}

National Cancer Institute

\section{Source}

National Cancer Institute. Rebound Tonometry. NCI Thesaurus. Code C120703.

A method in which a probe is bounced off of the surface of the cornea, creating an induction current that is used to calculate intraocular pressure. 